Check for updates

Cite this: RSC Adv., 2019, 9, 19217

Received 14th April 2019

Accepted 2nd June 2019

DOI: 10.1039/c9ra02819f

rsc.li/rsc-advances

\section{Layered composites composed of multi-walled carbon nanotubes/manganese dioxide/carbon fiber cloth for microwave absorption in the $X$ - band $\dagger$}

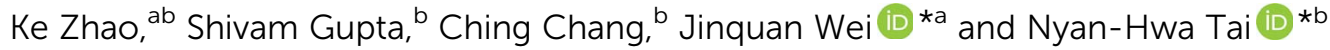

In this paper, multi-layered composites are fabricated for their application in electromagnetic interference (EMI) shielding. Composites of multi-walled carbon nanotubes/manganese dioxide $\left(\mathrm{MnO}_{2}\right)$ /epoxy are used as a microwave absorption layer, and a commercial carbon fiber cloth is used as a reflection layer. When the electromagnetic (EM) waves impinge on such layered composites, the absorption layer can absorb most of the EM waves, and the transmitted EM waves from the absorption layer will be reflected back by the reflection layer and absorbed by the absorption layer. Based on the rational design, the composites with four absorption layers and one reflection layer (with a total thickness of $2.85 \mathrm{~mm}$ ) show a high EMI shielding effectiveness of $41.24 \mathrm{~dB}$, while the average reflection loss of $13.62 \mathrm{~dB}$ can be attained in the $\mathrm{X}$-band (8.2-12.4 GHz). Moreover, the layered composites can absorb nearly $95 \%$ of the EM waves at the operating frequency, and provide an absorption dominant EMI shielding which are favorable for commercial and military applications.
\end{abstract}

\section{Introduction}

Nowadays, various electronics such as mobile phones, laptops, and wireless networks make our daily life very convenient. At the same time, they also cause electromagnetic interference (EMI) pollution, which not only disturbs neighbouring electronics and causes operational malfunction, but is also a hazard to human health and can cause damage to national defense security systems. ${ }^{1-3}$ Hence, high performance EMI shielding materials, especially electromagnetic (EM) wave absorbents, are in urgent demand to solve these problems by isolating the electronics from the surroundings.

Previously, metal-based materials are widely used in reflection-mode EMI shielding owing to their high electrical conductivity and high dielectric constant. ${ }^{4-6}$ However, they are also susceptible to chemical corrosion and heavy weight, which hinder their applications in the miniaturization of electronic devices. Polymers embedded with conductive fillers for EMI shielding have attracted much interest in recent years. ${ }^{7-16}$ Among the broad variety of polymers suitable for EMI shielding

${ }^{a}$ State Key Lab of New Ceramics and Fine Processing, School of Materials Science and Engineering, Key Lab for Advanced Materials Processing Technology of Education Ministry, Tsinghua University, Beijing, P. R. China.E-mail: jqwei@tsinghua.edu.cn; Tel: +86-10-62781065

${ }^{b}$ Department of Materials Science and Engineering, National Tsing-Hua University, Hsinchu, Taiwan. E-mail: nhtai@mx.nthu.edu.tw; Tel: +886-3-5715131 ext. 42568

$\dagger$ Electronic supplementary information (ESI) available. See DOI: 10.1039/c9ra02819f applications, epoxy resin (EP) is a good candidate because of easy processing, oxidation resistance, stability in normal environment, and commercial popularity. ${ }^{12,13}$ Besides, other polymers like polyvinylidene fluoride (PVDF), ${ }^{7}$ polycarbonate (PC) ${ }^{14}$ poly(lactic acid), ${ }^{15}$ and polypropylene ${ }^{16}$ have also been studied. Metallic fillers, carbonaceous fillers and conductive conjugated polymers are commonly used to increase conductivity of the polymer matrix. Theoretically, high aspect ratio and uniform distribution of fillers contribute to the rapid establishment of conductive networks in matrix. ${ }^{17}$ Multi-walled carbon nanotubes (MWCNTs), which are widely used as fillers in composites, have high aspect ratio, low density, high carrier mobility along the axial direction and outstanding mechanical properties. ${ }^{18,19}$ Owing to their high conductivity, MWCNTs/polymer composites were frequently reported as reflection-dominant shielding materials with shielding effectiveness proportional to the concentration of MWCNTs in matrix. ${ }^{12,20-22}$

However, microwave reflection is still undesirable because the reflected waves may bring negative effects to the surroundings. High-performance EM wave absorbers have attracted much attention recently. ${ }^{23-26}$ According to the EM theory, magnetic materials such as $\mathrm{Fe}, \mathrm{Co}, \mathrm{Ni}$, carbonyl iron and ferrites can consume the EM energy by natural ferromagnetic resonance and magnetic domain wall resonance ${ }^{27}$ while dielectric absorbers, including transition metal oxides like $\mathrm{ZnO}$, $\mathrm{TiO}_{2}$, and $\mathrm{MnO}_{2}$ can attenuate EM waves by natural resonance and polarization relaxation. ${ }^{28-30}$ Additionally, carbonaceous materials and conjugated polymers can block EM radiation 
ascribe to their high conductivity. $\mathrm{MnO}_{2}$ has been regarded as one of the most promising microwave dielectric materials due to its many advantages, such as natural abundance, low cost, environment-friendly nature, thermal stability, broad bandwidth and high dielectric loss in the gigahertz frequency range. ${ }^{30-35}$

Besides the coupling of magnetic and electric dipoles induced by magnetic and dielectric components, respectively, it was reported that the structural design also plays an important role in EMI shielding performance. Particularly, multi-layered structures have attracted numerous interest. ${ }^{36-38}$ Biswas et al. designed a multi-layered assembly which was composed of binary blends of PC and PVDF with $\alpha-\mathrm{MnO}_{2}$-doped MWCNTs and ferrite-doped cross-linked graphene oxide (GO) network, resulting in an impressive shielding effectiveness (SE) of $57 \mathrm{~dB}$ for a film with thickness of only $0.9 \mathrm{~mm} .{ }^{37}$ Zhao et al. successively deposited polyaniline and magnetic $\mathrm{Co} / \mathrm{Ni}$ alloy on commercial lyocell fabrics and achieved relatively high EMI SE of 33.95-46.22 dB within the X-band frequency. ${ }^{38}$

In view of the mentioned considerations, we designed a unique and easily-fabricated multi-layered structure with highly-efficient microwave absorption in X-band. The structure was composed of two layers: the first layer functioned as an absorption layer which was obtained by mixing EP with hybrid nanofillers consisting of MWCNTs and $\mathrm{MnO}_{2}$, and the second layer functioned as a reflection layer using a commercially available carbon fiber (CF) cloth. This design could be directly used in many areas like packaging, electronics and communication, which makes sure that almost no EM waves could penetrate out of the device and reduces the possibility of selfdisturbance. Mechanisms of EMI shielding were studied and the microstructure and morphology were characterized using field emission scanning electron microscope (FESEM), X-ray diffraction (XRD) and Raman spectroscopy.

\section{Experimental}

\subsection{Materials}

Potassium permanganate $\left(\mathrm{KMnO}_{4}\right)$ and manganese sulfate mono-hydrate $\left(\mathrm{MnSO}_{4} \cdot \mathrm{H}_{2} \mathrm{O}\right)$ with analytical grade were purchased from the Uni-Onward Corporation and used as received. MWCNTs powders with diameter of 20-30 nm and length of $1 \mu \mathrm{m}$ were obtained from the Golden Innovation Business Corporation. EP was purchased from the Hsin-Han Corporation, and the weight ratio of EP and hardener of $3: 1$ was used. CF cloth was supplied by the Formosa Plastics Corporation and acted as a reflection layer with a thickness of $0.85 \mathrm{~mm}$. Acetone and absolute ethanol were provided by the Echo Chemical Corporation Ltd.

\subsection{Synthesis of $\alpha-\mathrm{MnO}_{2}$}

$\alpha-\mathrm{MnO}_{2}$ nanorods were synthesized by an oil-bathing hydrothermal method ${ }^{31}$ at low temperature through the following reaction:

$3 \mathrm{MnSO}_{4} \cdot \mathrm{H}_{2} \mathrm{O}+2 \mathrm{MnO}_{4}{ }^{-} \rightarrow 3 \mathrm{SO}_{4}{ }^{2-}+4 \mathrm{H}^{+}+5 \mathrm{MnO}_{2} \downarrow+\mathrm{H}_{2} \mathrm{O}(1)$
As shown in Fig. 1a, in a typical process for synthesizing $\alpha$ $\mathrm{MnO}_{2}, 3.16 \mathrm{~g} \mathrm{KMnO}_{4}$ and $5.07 \mathrm{~g} \mathrm{MnSO}_{4} \cdot \mathrm{H}_{2} \mathrm{O}$ were dissolved in $160 \mathrm{~mL}$ deionized water successively at room temperature. Under vigorous magnetic agitation for $30 \mathrm{~min}$, the homogeneous dark-brown solution was transferred into an oil bath preset at $80^{\circ} \mathrm{C}$ and maintained for $18 \mathrm{~h}$. Subsequently, the solution was cooled down to room temperature naturally. The precipitates were centrifuged and rinsed with deionized water and absolute ethanol several times until the supernatant was neutral, and then dried at $100{ }^{\circ} \mathrm{C}$ for $24 \mathrm{~h}$. The obtained black powder was subjected to grind and was collected for characterization and the composite preparation.

\subsection{Preparation of $\mathbf{M W C N T s} / \mathrm{MnO}_{2} / \mathrm{EP}$ composites}

MWCNTs $/ \mathrm{MnO}_{2} / \mathrm{EP}$ composites were fabricated via a conventional casting method followed by hot-pressing, as depicted in Fig. 1b. Firstly, different weight ratios of MWCNTs, $\mathrm{MnO}_{2}$ nanorods and epoxy resin were mixed by magnetic stirring for $30 \mathrm{~min}$. In order to obtain a uniform dispersion of nanofillers, we introduced a three-roll mill (TR $35 \mathrm{~W}$, Yeong-Shin, Taiwan) to mix the composites, which could apply a large shear force on the hybrid. ${ }^{39}$ The gap between two parallel rollers was adjusted to $50 \mu \mathrm{m}$. The rotation speed was fixed at 150 rotations per minute. A mixture of MWCNTs, $\mathrm{MnO}_{2}$, and epoxy was fed into the machine for twenty times.

At the same time, the $\mathrm{CF}$ cloth was cut into rectangular shapes with size of $10 \times 9 \mathrm{~cm}^{2}$, and ultrasonic in acetone for $1 \mathrm{~h}$. After the CF cloth was rinsed with deionized water and absolute ethanol several times and dried at $60{ }^{\circ} \mathrm{C}$ for $24 \mathrm{~h}$, the clean CF cloth was cut into several pieces with an area of $3 \times 2$ $\mathrm{cm}^{2}$ each for the subsequent composite preparation.

Then, a mixture of MWCNTs, $\mathrm{MnO}_{2}$ and epoxy was poured into a mold where the $\mathrm{CF}$ cloth and a release paper were preplaced. The sample was cured under a pressure of $2000 \mathrm{~kg}$ $\mathrm{m}^{-3}$ at $70{ }^{\circ} \mathrm{C}$ for $0.5 \mathrm{~h}$ followed by a post curing under $120^{\circ} \mathrm{C}$ for $1 \mathrm{~h}$.

The sample indexes are described in Table 1. In the table, $X$ and $Y$ represent weight ratios of MWCNTs and $\mathrm{MnO}_{2}$, respectively, whereas $N$ represent the number of absorption layers. For example, a layered composite named as 1/10 has one layer of

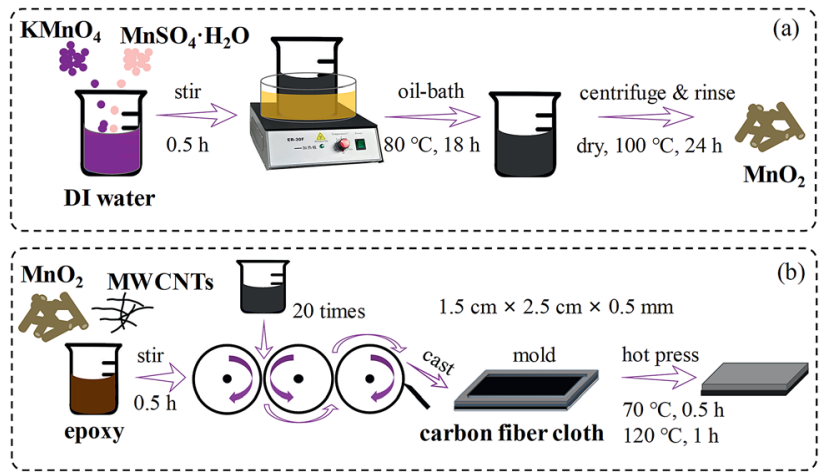

Fig. 1 Schematic representation of the fabrication process for (a) $\mathrm{MnO}_{2}$ nanorods, (b) layered composites. 
Table 1 Sample identification

\begin{tabular}{lll}
\hline Sample name & Contents (wt\%) & Structure \\
\hline$X / Y$ & $X \%$ MWCNTs $+Y \% \mathrm{MnO}_{2}$ & One layer of composites \\
$X / Y \times N$ & $X \%$ MWCNTs $+Y \% \mathrm{MnO}_{2}$ & $N$ layers of composites \\
$X / Y \times N+\mathrm{CF}$ & $X \%$ MWCNTs $+Y \% \mathrm{MnO}_{2}$ & $N$ layers of composites + CF cloth
\end{tabular}

MWCNTs $/ \mathrm{MnO}_{2} / \mathrm{EP}$ composite composed of $1 \mathrm{wt} \%$ MWCNTs and $10 \mathrm{wt} \% \mathrm{MnO}_{2}$ in the epoxy matrix. The sample of $1 / 10 \times 2+$ $\mathrm{CF}$ means two layers of $\mathrm{MWCNTs} / \mathrm{MnO}_{2} / \mathrm{EP}$ composites with $1 \mathrm{wt} \%$ MWCNTs and $10 \mathrm{wt} \% \mathrm{MnO}_{2}$ in the epoxy matrix on a CF cloth.

\subsection{Characterization}

The samples were characterized by using a field emission scanning electron microscope (FESEM, Hitachi SU-8010), Raman spectroscopy (Ram HR800, $632.8 \mathrm{~nm}$ ), X-ray diffraction (XRD, Bruker D2 Phase, Cu-K $\alpha$ radiation, $\lambda=1.5406 \AA$ ). Sheet resistivity was measured by a four-probe electric measuring instrument (CT5601Y, Chitai Electronic Corporation) connected with a semiconductor characterization system of Keithley 4200-SCS.

\section{$2.5 \quad$ EM measurements}

The scattering parameters $\left(S_{11}\right.$ and $\left.S_{21}\right)$ of each sample were measured by vector network analyzer (VNA, Alight Technologies, E8364A, PNA series Network Analyzer) using waveguide sample holder in X-band frequency range $(8.2-12.4 \mathrm{GHz})$ at room temperature. The VNA setup was calibrated carefully before each measurement. Layered composite samples were prepared with dimensions of $2.5 \times 1.5 \mathrm{~cm}^{2}$, so as to accommodate the X-band waveguide holder. The samples with different weight ratios and thicknesses were placed in the specimen holder. The scattering parameters of each sample were recorded and transferred into $\mathrm{SE}_{\mathrm{T}}$ (total shielding effectiveness) and $\mathrm{SE}_{\mathrm{R}}$ (reflection shielding effectiveness) automatically by the software.

\section{Results and discussion}

\subsection{Structure and morphology}

Fig. 2a shows a SEM image of the MWCNTs which are entangled together. The MWCNTs are highly pure as nearly no impurity are observed during SEM examination. Fig. 2b depicts a Raman spectrum of the MWCNTs. The intensity ratio of D-band to Gband $\left(I_{\mathrm{D}} / I_{\mathrm{G}}\right)$ is 1.37 , implying lots of defects in the MWCNTs. Straight $\mathrm{MnO}_{2}$ nanorods synthesized from the oil-bathing hydrothermal method have smooth surfaces (see Fig. 2c), which are similar to those in Guan's report. ${ }^{31}$ Fig. $2 d$ shows a XRD curve of the $\mathrm{MnO}_{2}$ nanorods. The XRD curve is consistent with that of the $\alpha-\mathrm{MnO}_{2}$ (JCPDS 44-0141), which implies that our samples are mainly $\alpha-\mathrm{MnO}_{2}$ nanorods. We believe that the growth of the $\alpha-\mathrm{MnO}_{2}$ nanorods follow the mechanism proposed by Guan et al. ${ }^{31} \mathrm{In}$ brief, the $\alpha-\mathrm{MnO}_{2}$ nanorods grow through a redox reaction between $\mathrm{Mn}^{2+}$ and $\mathrm{MnO}_{4}{ }^{-}$in $1 \mathrm{D}$ growth habit.
Fig. 2e shows a SEM image of fracture surface of the MWCNTs $/ \mathrm{MnO}_{2} / \mathrm{EP}$ composite. The $\mathrm{MnO}_{2}$ nanorods, marked by ovals, show a relative rigidity; whereas the MWCNTs with curled configuration are indicated by arrows. The fracture surface of the epoxy matrix, having a typical smooth surface, is also detected in the SEM image. By applying high shear stress via a three-roll mill, the entangled MWCNTs and straight $\mathrm{MnO}_{2}$ nanorods disperse uniformly in the epoxy matrix.

Fig. 2f shows XRD curves of the $\mathrm{MWCNT} / \mathrm{MnO}_{2} / \mathrm{EP}$ composites and their constituent phases. There is a broad XRD peak centred at $18^{\circ}$ in the XRD curve of the epoxy matrix (black), corresponding to the amorphous state of epoxy. ${ }^{40}$ The XRD peaks at $25.6^{\circ}$ and $42.9^{\circ}$ are associated with the graphitic
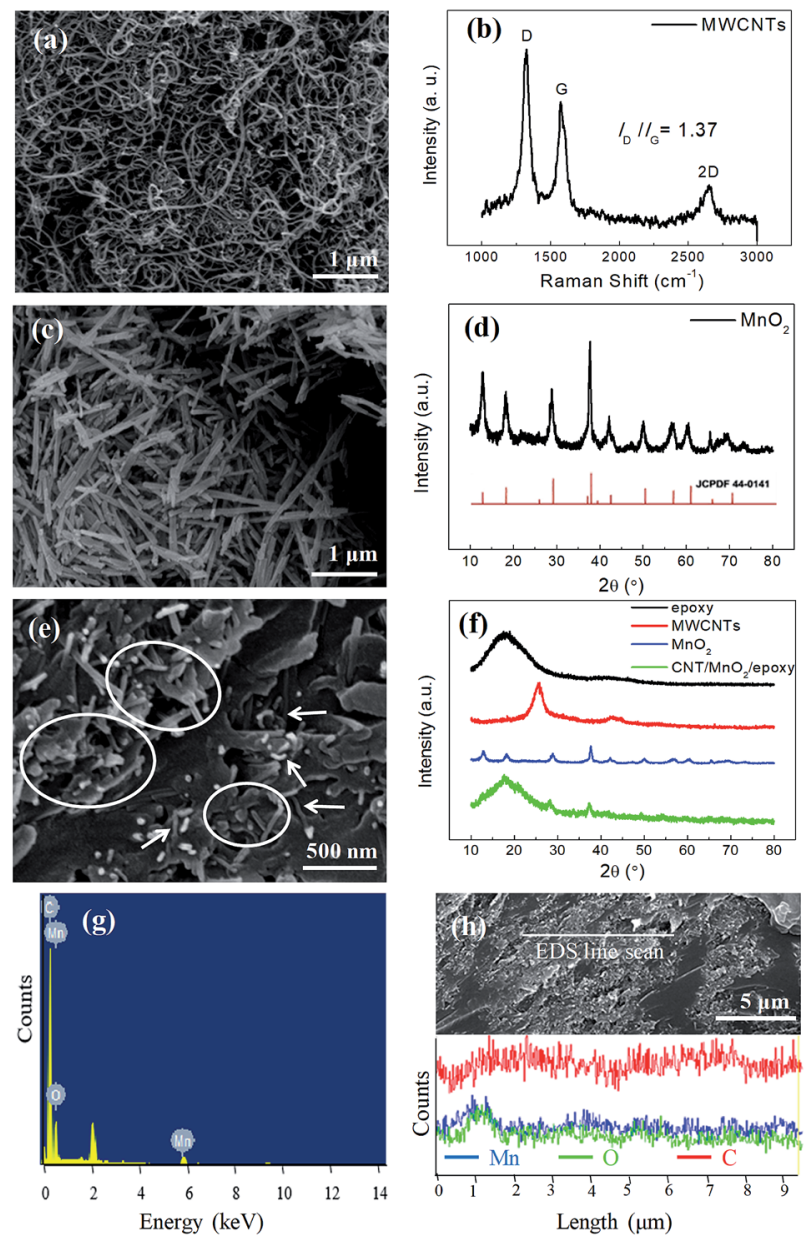

Fig. 2 Characterization of MWCNTs, $\mathrm{MnO}_{2}$, and their composites. SEM images of (a) MWCNTs, (c) $\mathrm{MnO}_{2}$ and (e) composites with $1 \mathrm{wt} \%$ of MWCNTs and $10 \mathrm{wt} \%$ of $\mathrm{MnO}_{2}$ in epoxy matrix, (b) Raman spectrum of MWCNTs, XRD curves of (d) $\mathrm{MnO}_{2}$ and (f) composites and their constituent phases, ( $g$ ) elemental analysis using EDS and (h) elemental line analysis of $\mathrm{MWCNTs} / \mathrm{MnO}_{2} / \mathrm{EP}$ composites. 
structure of (002) and (100) plane diffraction (JCPDS 01-0646) in the MWCNT sample (red), respectively. All the diffraction peaks in the as-prepared $\mathrm{MnO}_{2}$ can be easily indexed to tetragonal $\alpha$ $\mathrm{MnO}_{2}$ phase (JCPDS 44-0141), which is generally regarded as the most suitable type among the various crystalline states of $\mathrm{MnO}_{2}$ for EMI shielding. ${ }^{30}$ In addition, there is no other diffraction peaks from impurity, which suggests the high purity of our samples. Fig. 2f also shows an XRD curve of the MWCNTs/ $\mathrm{MnO}_{2} / \mathrm{EP}$ composites with $1 \mathrm{wt} \%$ MWCNTs and $10 \mathrm{wt} \% \mathrm{MnO}_{2}$ (green). Besides epoxy, there are only some weak XRD peaks of $\mathrm{MnO}_{2}$ in the XRD curve owing to the low concentration. However, FESEM images and EDS elemental analysis verify the existence of MWCNTs and $\mathrm{MnO}_{2}$ in the composites.

Elemental analysis of MWCNTs/ $\mathrm{MnO}_{2} / \mathrm{EP}$ composites is performed over the sample surface to visualize the atomic elements of $\mathrm{C}, \mathrm{Mn}$ and $\mathrm{O}$. Three elements in the absorption layer can be detected according to the EDS elemental analysis results (Fig. 2g). It is obvious that carbon (C) comes from epoxy and MWCNTs, manganese (Mn) from $\mathrm{MnO}_{2}$ and oxygen (O) from epoxy and $\mathrm{MnO}_{2}$. Fig. $2 \mathrm{~h}$ indicates a nearly homogeneous elemental distribution of $\mathrm{C}$ and $\mathrm{Mn}$ across one randomly selected scanning line on the absorption layer. MWCNTs are uniformly dispersed and embedded among dielectric $\mathrm{MnO}_{2}$ throughout the epoxy matrix. The homogeneous network increases the conductivity of the absorption layer and leads to more conductive loss and inside multi-reflection.

Morphologies of the CF cloth are shown in Fig. S1a and b. $\dagger$ The digital photo shows criss-cross CF bundles shining with metallic luster. It can be seen from the SEM image that the CF bundles have smooth surface and dimeter of $\sim 7.5 \mu \mathrm{m}$. As shown in Fig. S1c, $\dagger$ there are two prominent Raman peaks at 1350 and $1580 \mathrm{~cm}^{-1}$ in the Raman spectrum of CF, corresponding to $\mathrm{G}$-band and $\mathrm{D}$-band of $\mathrm{CF}$, respectively. The intensity ratio of D-band to G-band $\left(I_{\mathrm{D}} / I_{\mathrm{G}}\right)$ is 1.10 , showing high crystallinity of the CF. ${ }^{41}$ Fig. S1d $\dagger$ shows the XRD pattern of the CF cloth. There is a strong XRD peak centred at $24.9^{\circ}$, corresponding to the graphitic structure of (002) plane. A weak peak appears at $43.2^{\circ}$, which relates to the (100) plane of graphite structure.

\subsection{Electrical properties}

By adding MWNCTs to the composites, the sheet resistivity decreases significantly from $10^{7}$ to $10^{3} \Omega \mathrm{sq}^{-1}$ (Fig. 3a), which is ascribed to homogeneous dispersion of the high conductive MWCNTs. They establish a conducting network in the MWCNTs $/ \mathrm{MnO}_{2} /$ EP composites. As shown in Fig. $3 \mathrm{~b}$, the sheet resistivity is slightly reduced with the increasing amount of $\mathrm{MnO}_{2}$ in the composites, although $\mathrm{MnO}_{2}$ is an electric insulator. The presence of $\mathrm{MnO}_{2}$ in the composite helps for MWCNT dispersion. As a result, it generates better electric network and improves the electric conductivity.

In addition, the SEM images depicted in Fig. $3 \mathrm{a}$ and $\mathrm{b}$ indicate uniform dispersion of MWCNTs (white spots) in the composites. Higher MWCNTs concentration with uniform dispersion creates an intensive electric network which effectively reduces the sheet resistivity. Based on the above results, it
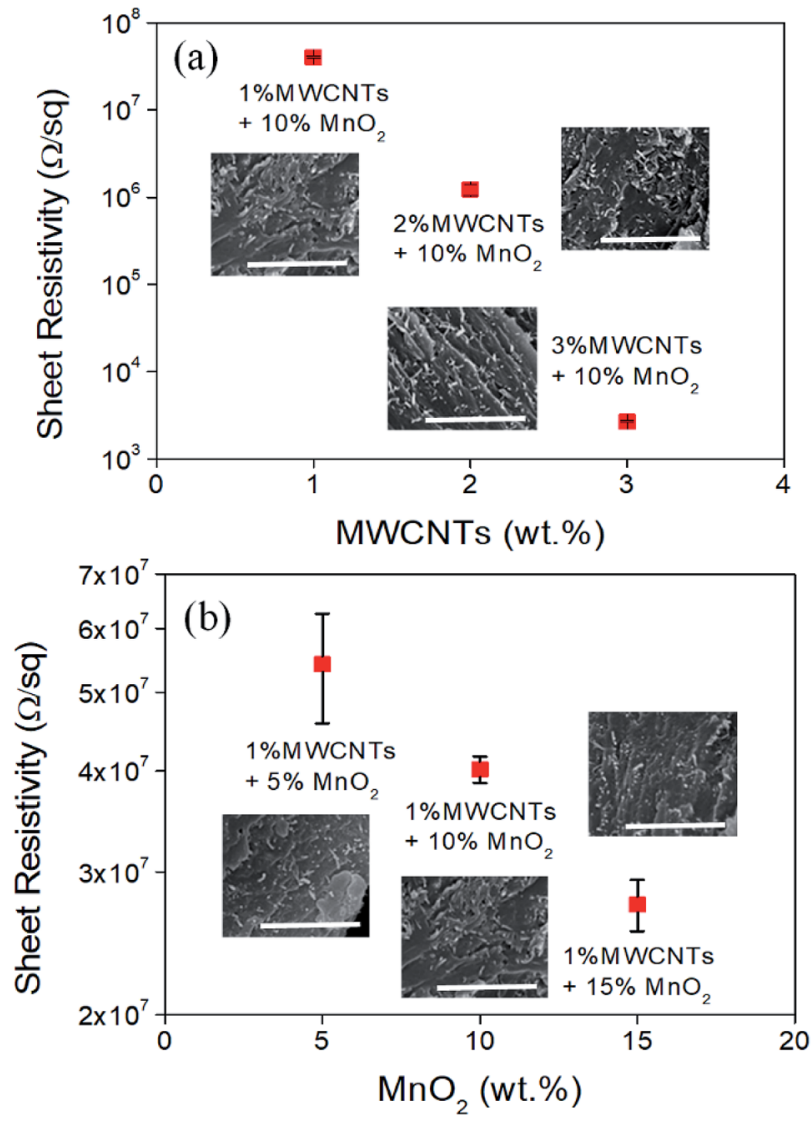

Fig. 3 Sheet resistivity of the $\mathrm{MWCNTs} / \mathrm{MnO}_{2} / \mathrm{EP}$ composites with (a) different MWCNTs concentrations and (b) different $\mathrm{MnO}_{2}$ concentrations. All inset scale bars are $2.5 \mu \mathrm{m}$.

is concluded that the concentration of MWCNTs in the composites dominates the electrical conductivity of the composites.

\subsection{Microwave absorption properties}

According to transmission line theory, experimental shielding performance can be estimated as

$$
\mathrm{SE}_{\mathrm{T}}=\mathrm{SE}_{\mathrm{R}}+\mathrm{SE}_{\mathrm{A}}+\mathrm{SE}_{\mathrm{M}}=10 \log \left(\frac{P_{\text {in }}}{P_{\text {out }}}\right)
$$

where $\mathrm{SE}_{\mathrm{A}}, \mathrm{SE}_{\mathrm{M}}, P_{\text {in }}$ and $P_{\text {out }}$ represent absorption loss, multireflection loss, incident and transmitted EM power, respectively. ${ }^{42}$ Besides, $\mathrm{SE}_{\mathrm{R}}, \mathrm{SE}_{\mathrm{A}}$ and $\mathrm{SE}_{\mathrm{M}}$ losses can be calculated by the following formulas: ${ }^{43,44}$

$$
\begin{gathered}
\mathrm{SE}_{\mathrm{A}}=1.314 t \sqrt{f \mu_{\mathrm{r}} \sigma_{\mathrm{r}}}=20 \log \left|\frac{Z_{\text {in }}-1}{Z_{\text {in }}+1}\right| \\
\mathrm{SE}_{\mathrm{R}}=168-10 \log \left(\sqrt{\frac{f \mu_{\mathrm{r}}}{\sigma_{\mathrm{r}}}}\right) \\
\mathrm{SE}_{\mathrm{M}}=20 \log \left(1-\exp \left(\frac{-2 t}{\delta}\right)\right)
\end{gathered}
$$




$$
\begin{gathered}
Z=\sqrt{\frac{\mu}{\varepsilon}} \\
\delta=\frac{1}{\sqrt{\pi \mu \sigma f}}
\end{gathered}
$$

where $f$ is the frequency of EM waves, $Z_{\text {in }}$ is the input impedance, $\sigma$ is the electrical conductivity, $\mu$ is the magnetic permeability, $\varepsilon$ is the dielectric permittivity, $t$ is the thickness of hybrid composites, and $\delta$ is the skin depth. The skin depth stands for the depth where incident EM energy decays to $\mathrm{e}^{-1}$ of its original intensity, which is defined in eqn (7). $\mathrm{SE}_{\mathrm{M}}$ is usually neglected in bulk materials if $\mathrm{SE}_{\mathrm{T}}$ is greater than $15 \mathrm{~dB} .^{7}$ From these equations, one can get a qualitative understanding that high conductivity, high dielectric permittivity and high magnetic permeability are favorable to shielding materials.

According to the eqn (3)-(7), it is obvious that electrical conductivity is a critical factor for $\mathrm{SE}_{\mathrm{R}}$ loss. High conductivity always brings low $\mathrm{SE}_{\mathrm{R}}$ loss, that is to say, reflects more EM waves from the surface of the shielding materials because of impedance mismatch which can be quantified by the ratio of free space impedance $\left(Z_{0}\right.$, approximately equals to $\left.377 \Omega\right)$ to input impedance $\left(Z_{\text {in }}\right)$. The higher the ratio, the more the reflection will be. Higher conductive materials have lower input impedance, which result in higher impedance mismatch and subsequently more reflection of the impinging EM waves. On the contrary, materials with higher input impedance allow more EM waves to penetrate through the surface, which is beneficial to the absorption. ${ }^{45}$

The absorbed EM waves convert to heat and subsequently dissipate to environment. Apparently, $\mathrm{SE}_{\mathrm{A}}$ can be influenced by electrical conductivity, magnetic permeability, dielectric permittivity, as well as operating frequency and the thickness of the absorber. ${ }^{46}$ In order to increase the $\mathrm{SE}_{\mathrm{R}}$ loss and reduce the reflection of the impinging EM wave, it is suggested that using a conductive material with proper conductivity is a good strategy for the objective.

Fig. $4 \mathrm{a}$ and $\mathrm{b}$ illustrate $\mathrm{SE}_{\mathrm{T}}$ and $\mathrm{SE}_{\mathrm{R}}$ of the single layer composite. It shows that the $1 / 10$ sample ( $1 \mathrm{wt} \%$ MWCNTs) possesses the lowest $\mathrm{SE}_{\mathrm{T}}$ but has the highest $\mathrm{SE}_{\mathrm{R}}$ among three samples of $1 / 10,2 / 10$ and $3 / 10$. It implies that EM waves can transmit through the sample with low MWCNT concentration more easily than that with high MWCNT concentration. And, the sample with lower MWCNT concentration can reflect less EM waves. A similar study is performed on the samples containing different contents of $\mathrm{MnO}_{2}$. Surprisingly, the $\mathrm{SE}_{\mathrm{T}}$ and $\mathrm{SE}_{\mathrm{R}}$ of the samples with the $\mathrm{MnO}_{2}$ concentration of $1 / 5,1 / 10$, and $1 / 15$ possess nearly similar transmission loss and reflection loss, as shown in Fig. $4 \mathrm{c}$ and $\mathrm{d}$.

Fig. $5 \mathrm{a}$ and $\mathrm{b}$ separately show $\mathrm{SE}_{\mathrm{T}}$ and $\mathrm{SE}_{\mathrm{R}}$ of the $1 / 10, \mathrm{CF}$, and $1 / 10+C F$ samples. As expected, the sample of 1/10 possesses the lowest $\mathrm{SE}_{\mathrm{T}}$, while the other two samples, $\mathrm{CF}$ and $1 / 10+\mathrm{CF}$, have similar high $\mathrm{SE}_{\mathrm{T}}$ (see Fig. 5a). However, as depicted in Fig. 5b, the $\mathrm{CF}$ has the lowest $\mathrm{SE}_{\mathrm{R}}$, and 1/10 + CF sample possesses higher $\mathrm{SE}_{\mathrm{R}}$ than the $\mathrm{CF}$. It is explained that when the EM waves impinge 1/10 absorption layer, some of them transmit through the layer and reflect by the CF, and then
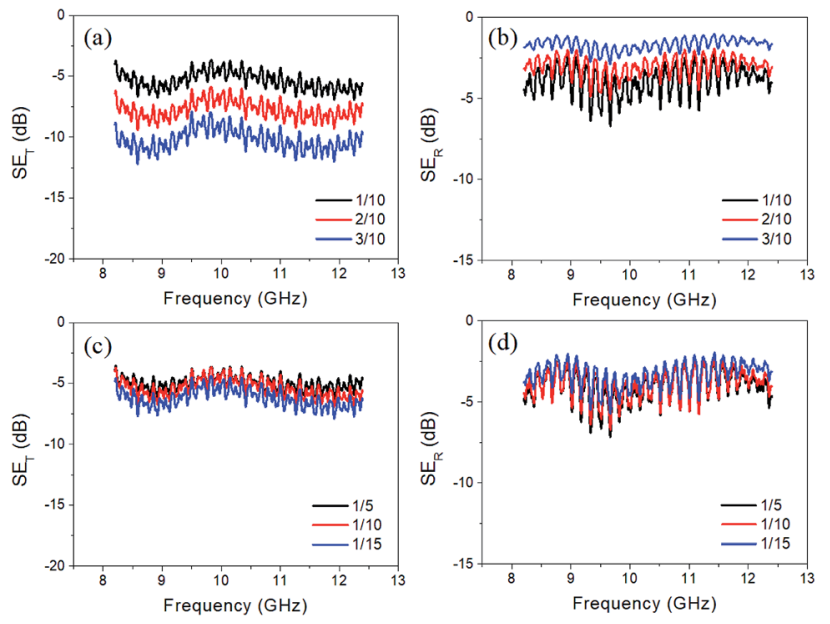

Fig. 4 Illustration of (a) $\mathrm{SE}_{\mathrm{T}}$ and (b) $\mathrm{SE}_{\mathrm{R}}$ of the single layer composite with different MWCNT concentrations and (c) $S E_{T}$ and (d) $S E_{R}$ of the composites with different $\alpha-\mathrm{MnO}_{2}$ concentrations.

absorb again by the absorption layer. The double absorption results in the higher $\mathrm{SE}_{\mathrm{R}}$ of the $1 / 10+\mathrm{CF}$ sample than that of the CF. Based on the results of $\mathrm{SE}_{\mathrm{T}}$ and $\mathrm{SE}_{\mathrm{R}}$ for the building blocks of the composites, and to make the utmost use of the advantages of conductive carbonaceous materials and dielectric $\mathrm{MnO}_{2}$, we select CF cloth as the reflection layer and MWCNTs/ $\mathrm{MnO}_{2} / \mathrm{EP}$ composites with $1 \mathrm{wt} \%$ MWCNTs and $10 \mathrm{wt} \% \mathrm{MnO}_{2}$ in the epoxy matrix as the absorption layer. The plots of $\mathrm{SE}_{\mathrm{T}}$ and $\mathrm{SE}_{\mathrm{R}}$ versus frequency for the multi-layered composites having five different layer numbers and $\mathrm{CF}$ reflection layer are shown in Fig. $5 \mathrm{c}$ and $\mathrm{d}$.

When we increase the thickness of the layered composites to an extent, as shown in Fig. 5c, the total shielding effectiveness with different layer numbers are similar and with an average value as high as $41 \mathrm{~dB}$. It means that less than $0.01 \%$ of incident
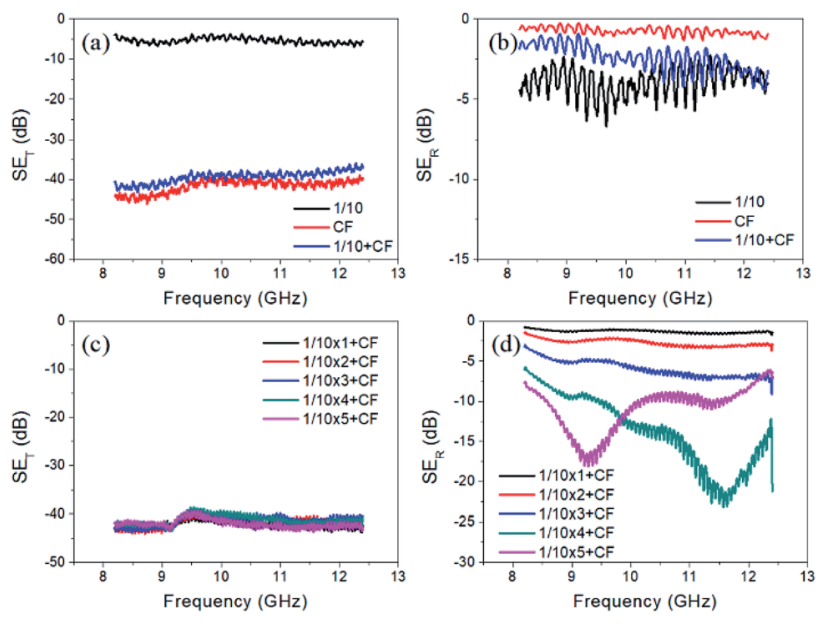

Fig. $5 \mathrm{SE}_{\mathrm{T}}$ and $\mathrm{SE}_{\mathrm{R}}$ plots of the layered composites and constituent layers. (a) $S E_{T}$ and (b) $S E_{R}$ of the 1/10, CF, and 1/10 + CF samples, (c) $S E_{T}$ and (d) $\mathrm{SE}_{\mathrm{R}}$ of the layered composites with different absorption layer numbers. 
EM waves can transmit the designed shielding materials. In other words, the multi-layered composites could completely satisfy commercial requirements on EMI shielding. In this work, we find that $\mathrm{SE}_{\mathrm{R}}$ loss is very sensitive to the thickness of the absorbing material. When we use only one absorption layer $(0.5 \mathrm{~mm})$ or two absorption layers $(1.0 \mathrm{~mm}), \mathrm{SE}_{\mathrm{R}}$ is lower than 5 $\mathrm{dB}$, as shown in Fig. $5 \mathrm{~d}$. It implies that EM waves can penetrate through the thin absorption layer easily, and subsequently almost all of them will be reflected back by the highlyconductive $\mathrm{CF}$ cloth. The higher $\mathrm{SE}_{\mathrm{R}}$ loss, the lower amount of EM waves can be reflected from the surface. When the layer number further increases, one can see that reflection loss becomes higher, which implies more EM waves are absorbed according to the eqn (2). At four layers of absorption composites $(2.0 \mathrm{~mm})$, the absorption peak is located at $11.6 \mathrm{GHz}$ with a $\mathrm{SE}_{\mathrm{R}}$ loss of $23.22 \mathrm{~dB}$, and the effective absorption bandwidth $\left(\mathrm{SE}_{\mathrm{R}}\right.$ loss higher than $10 \mathrm{~dB}$ ) reaches $2.9 \mathrm{GHz}$ (from 9.5 to $12.4 \mathrm{GHz}$ ) at the test frequency range. If the layer number further increases to five $(2.5 \mathrm{~mm})$, the sample has a less absorption peak of 18.12 $\mathrm{dB}$ at $9.2 \mathrm{GHz}$, and its effective absorption bandwidth decreases to $1.5 \mathrm{GHz}$ (from 8.6 to $10.1 \mathrm{GHz}$ ). Table 2 shows comparison of $\mathrm{SE}$ values of the multi-layered composite with the $\mathrm{MnO}_{2}$-based EMI shielding materials in literature. It shows that the present work is clearly comparable in terms of thickness and the SE values. Our layered composites show high SE value with relative low loading of $\mathrm{MnO}_{2}$.

The absorption peak (the same position as the reflection peak) shifts to a lower frequency band when the layer number increases from four to five, as shown in Fig. $5 \mathrm{~d}$. It could be explained using the quarter wavelength cancellation model. When the thickness of the absorber equals to odd-numbered multiple of the quarter incident wavelength, the reflected and incident waves will interfere each other in composites, and cancel out at the air/composite interface and inside the shielding materials. ${ }^{33,35}$ This phenomenon results from the resonant absorption in low permittivity materials and is attributed to the decrease of the matching frequency along with the increasing thickness. ${ }^{31}$

As mentioned above, high electric conductivity plays a negative effect on EM wave absorption because of the impedance mismatch. Dielectric loss originates from electronic polarization, ionic polarization, dipole orientation polarization, interfacial polarization and associated relaxation phenomena. The former two polarizations usually take place in the ultraviolet or infrared frequency range, thus can be negligible in $\mathrm{X}$ band frequency. ${ }^{36,37}$ Magnetic loss stems from the resonance phenomenon. Apart from conductivity, complex permittivity $(\varepsilon$, $\left.\varepsilon=\varepsilon^{\prime}-\mathrm{i} \varepsilon^{\prime \prime}\right)$ and permeability $\left(\mu, \mu=\mu^{\prime}-\mathrm{i} \mu^{\prime \prime}\right)$ of the $(1 / 10 \times 4+$ $\mathrm{CF}$ ) sample can be calculated using the NRW conversion method. ${ }^{47,48}$ As shown in Fig. 6, the complex permittivity and permeability are frequency-dependent. The real part $\varepsilon^{\prime}$ (and $\mu^{\prime}$ ) is associated with the ability to store energy in electric (and magnetic) field, while the imaginary part $\varepsilon^{\prime \prime}$ and $\mu^{\prime \prime}$ corresponds to the loss of energy within the material resulting from conduction, resonance, and relaxation mechanisms. ${ }^{31}$ It can be seen from Fig. 6 a that real part of the permittivity of the $(1 / 10 \times$ $4+\mathrm{CF}$ ) sample has an average value of about 0.6 , while its imaginary part has a value of about 5.5 with a small fluctuation in the whole $\mathrm{X}$-band frequency. $\mathrm{MnO}_{2}$ is a dielectric material with very poor conductivity. The low value of the real part of the permittivity implies better impedance matching in the composites. Cyclic polarization and vibration of the electric and magnetic dipoles results in microwave absorption. The $\mathrm{MnO}_{2}$ nanorods has larger specific surface, which contribute to interfacial polarization and scattering of the incident EM waves. In Fig. 6b, a sharp decline for real part of permeability from 21.6 at $8.2 \mathrm{GHz}$ to almost zero in high frequency can be detected. At the same time, severe fluctuations occurs in the imaginary part of permeability. $\alpha-\mathrm{MnO}_{2}$ is an antiferromagnetic material. Therefore, the magnetic response may be ascribed to the ferromagnetic coupling of $\mathrm{MnO}_{2}$ and MWCNTs, which refers to the interactions between electrons and $\mathrm{Mn}$ ions in the conductive network. Even so, magnetic loss tangent $\left(\tan \delta_{\mathrm{m}}=\right.$ $\mu^{\prime \prime} / \mu^{\prime}$ ) of the composites is still very low. In other words, dielectric loss is the main contributing factor of EMI shielding in our designed structure.

In order to investigate the mechanism of multi-layered structure, we calculate the transmission coefficient $(T)$, reflection coefficient $(R)$, and absorption coefficient $(A)$ from $\mathrm{SE}_{\mathrm{T}}$ and $\mathrm{SE}_{\mathrm{R}}$ using the following equations: ${ }^{34}$

$$
T+R+A=1
$$

Table 2 Optimum SE (dB) of some $\mathrm{MnO}_{2}$ composites with present work

\begin{tabular}{|c|c|c|c|c|c|}
\hline $\mathrm{MnO}_{2}$ nanowires/wax & $25 \mathrm{wt} \%$ & $2-12$ & 4 & 21.7 & 30 \\
\hline $\mathrm{MnO}_{2}$ nanorods/wax & $25 \mathrm{wt} \%$ & $2-18$ & 3 & 25 & 31 \\
\hline $\mathrm{MnO}_{2} /$ graphene nanoribbons & $86 \mathrm{wt} \%$ & $12.4-18$ & 3 & 57 & 32 \\
\hline $\mathrm{MnO}_{2}$ nanorods & $100 \mathrm{wt} \%$ & $8.2-12.4$ & 2.18 & $20+$ & 50 \\
\hline $\mathrm{CS} @ \mathrm{MnO}_{2} / \mathrm{wax}$ & $12.35 \mathrm{wt} \%$ & $8-18$ & 2 & 23 & 51 \\
\hline $\mathrm{MnO}_{2}$ nanorods/PVB & $5 \mathrm{wt} \%$ & $8.2-18$ & 2 & 37 & 35 \\
\hline $\mathrm{MnO}_{2} /$ epoxy $+\mathrm{CB} /$ epoxy & $10 \mathrm{wt} \%$ & $8-18$ & 4.5 & 29 & 52 \\
\hline MWCNTs/ $\mathrm{MnO}_{2} /$ epoxy $+\mathrm{CF}$ cloth & $10 \mathrm{wt} \%$ & $8.2-12.4$ & 2.85 & 41 & This \\
\hline
\end{tabular}



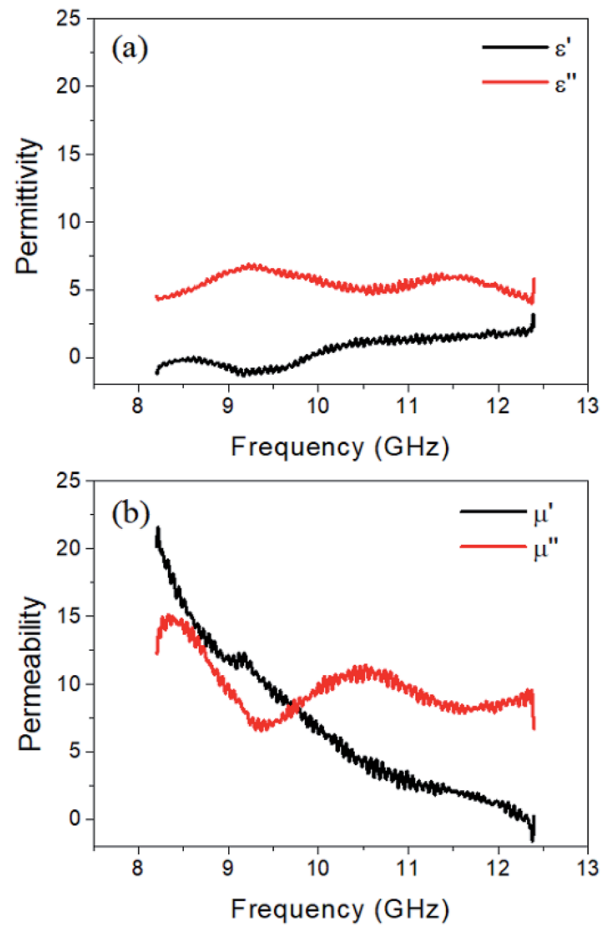

Fig. 6 Complex (a) permittivity and (b) permeability of the composites with the highest $\mathrm{SE}_{\mathrm{R}}$ loss.

$$
\begin{gathered}
\mathrm{SE}_{\mathrm{T}}=10 \log T=20 \log \left|S_{21}\right| \\
\mathrm{SE}_{\mathrm{R}}=10 \log (1-R)=10 \log \left(1-\left|S_{11}\right|^{2}\right)
\end{gathered}
$$

where, $T, R$ and $A$ indicate the capability of a material to transmit, reflect, and absorb the microwave, respectively. From the equations, lower $T$ implies less transmitted EM waves, higher $R$ represents less reflection, and lower $A$ implies more absorption.

Fig. $7 \mathrm{a}-\mathrm{c}$ show the calculation results of transmission, reflection, and absorption coefficients of the composites with different layer numbers. As the number of absorption layer increases from one to four, the reflection coefficient increases from 0.26 to 0.93 . On the contrary, the absorption coefficient decreases from 0.74 to 0.07 . These results show that the mechanism of our layered composites is changing from reflection-controlled shielding to absorption-dominant attenuation. However, when the layer number increases to five, there is a slight decrease in the reflection coefficient from 0.93 to 0.90 and a small increase in the absorption coefficient from 0.07 to 0.10 . Additionally, the peaks also shift to lower frequency. These results are consistent with $\mathrm{SE}_{\mathrm{R}}$ loss in Fig. $5 \mathrm{~d}$.

It is well recognized that thicker materials have better shielding effectiveness, but it seems inappropriate for the multi-layered composites. The layered-structure composites show better shielding performance than a single layer. The factors that determine absorption in a single layer are conductivity, complex permittivity and permeability, skin depth of the materials, and operating frequency. Nevertheless, it is necessary to take into account the impedance matching between different
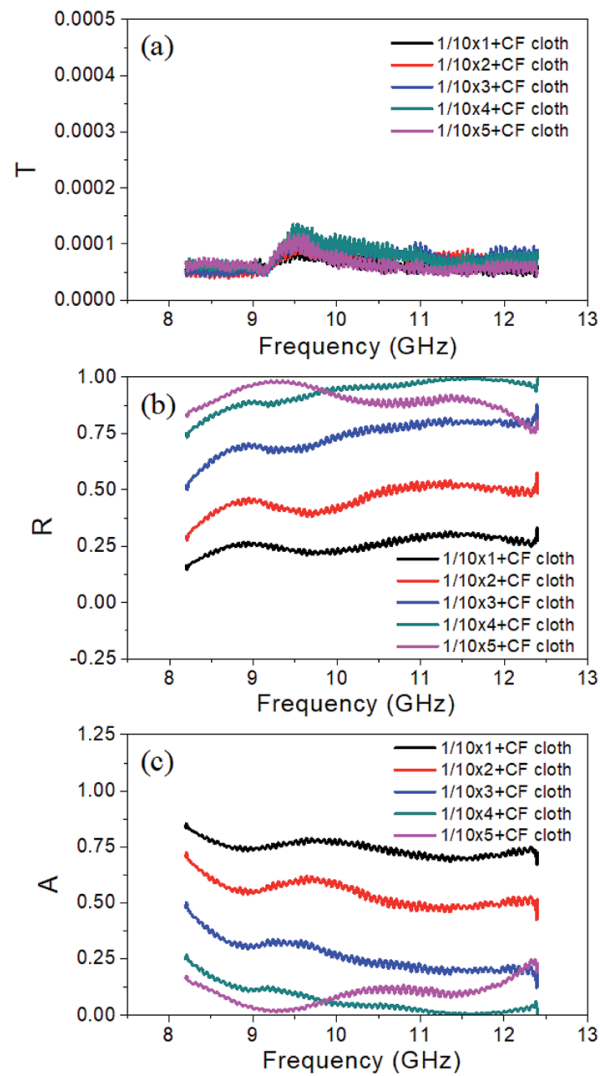

Fig. 7 (a) Transmission coefficient, (b) reflection coefficient and (c) absorption coefficient of the multi-layered composites with different absorption layer numbers.

layers and geometric design of each layer in the analysis of the absorption mechanism in multi-layered materials. According to the size effect, thinning of materials contributes to the absorption in high frequency range and vice versa. For highlyefficient absorption, the absorbers with maximum bandwidth are needed by employing applicable and suitable thickness. Impedance matching is another important factor that must be taken into consideration and the sequence of multiple layers needs to be arranged properly.

Fig. 8 shows possible EMI shielding mechanism in our multi-layered hybrid structure. Low content of MWCNTs in the epoxy matrix acts as an absorption layer with moderate conductive paths and forms a highly-efficient conductive network for facilitating the dissipation of EM energy. The incorporation of $\alpha-\mathrm{MnO}_{2}$ nanorods not only improves the dispersion of MWCNTs, but also increases the impedance matching so as to reduce the reflection of EM waves. In addition, uniform dispersion of high-aspect-ratio MWCNTs can contribute long pathway for carrier transport to form electric dipole, which consume the energy and subsequently enhance the $\mathrm{EM}$ wave absorption. Meanwhile, $\mathrm{MnO}_{2}$ induced dielectric attenuation plays a leading role in the absorption layer. With arranging the conductive $\mathrm{CF}$ cloth at the rear of the layered composites, minimum transmission of the EM waves can be attained because of a strong reflection shield. Owing to the 


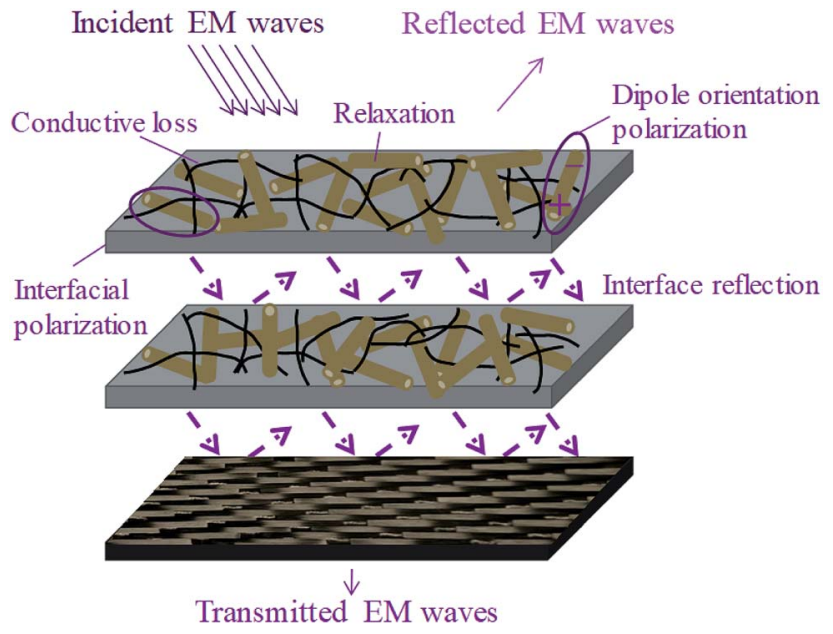

Fig. 8 Schematic illustration of possible attenuation mechanism

integration of chemical composition and unique structure, we make the utmost use of synergistic effect in designing the multilayered composites and achieve low-cost, easy-fabricated and high-efficiency absorption-dominant EMI shielding materials.

\section{Conclusions}

In summary, homogeneous distribution of $\alpha-\mathrm{MnO}_{2}$ nanorods and MWCNTs in the epoxy matrix endows the MWCNTs $/ \mathrm{MnO}_{2} /$ EP composites with optimized conductivity accompanying excellent microwave absorption ability. Multi-layered structure of the EMI shielding materials, using the MWCNTs/ $\mathrm{MnO}_{2} / \mathrm{EP}$ composites as absorption layer and CF cloth as reflection layer, are fabricated. With four absorption layers, a total EMI shielding effectiveness of $41.24 \mathrm{~dB}$ with reflection loss of $23.22 \mathrm{~dB}$ is achieved at $11.57 \mathrm{GHz}$, indicating that nearly $99.52 \%$ of the EM waves are absorbed by the designed attenuator. The multilayered composites utilize the synergistic effects of conductive MWCNTs and dielectric $\mathrm{MnO}_{2}$, and create multiple impedance mismatching. Thus, the multi-layered composites make the utmost of multi-reflection between each layer, and are promising microwave absorption materials in X-band.

\section{Conflicts of interest}

There are no conflicts to declare.

\section{Acknowledgements}

The authors are thankful for the funding support from the Ministry of Science and Technology, Taiwan under the contract MOST 107-2221-E-007-008-MY3.

\section{References}

1 S. Geetha, K. K. S. Kumar, C. R. K. Rao, M. Vijayan and D. C. Trivedi, J. Appl. Polym. Sci., 2010, 112, 2073.

2 D. D. L. Chung, J. Mater. Eng. Perform., 2000, 9, 350.
3 D. D. L. Chung, Carbon, 2001, 39, 279.

4 Y. Okazaki and K. Ueno, J. Magn. Magn. Mater., 1992, 112, 192.

5 C. H. Peng, H. W. Wang, S. W. Kan, M. Z. Shen, Y. M. Wei and S. Y. Chen, J. Magn. Magn. Mater., 2004, 284, 113.

6 H. J. Oh, V. D. Dao and H. S. Choi, Appl. Surf. Sci., 2018, 435, 7.

7 S. Biswas, G. P. Kar and S. Bose, J. Mater. Chem. A, 2015, 3, 12413.

8 Y. Chen, Y. Li, M. Yip and N. Tai, Compos. Sci. Technol., 2013, 80, 80 .

9 A. Ameli, P. U. Jung and C. B. Park, Carbon, 2013, 60, 379.

$10 \mathrm{~J}$. Wu, J. Chen, Y. Zhao, W. Liu and W. Zhang, Composites, Part B, 2016, 105, 167.

11 S. Kumar, G. Datt, A. S. Kumar and A. C. Abhyankar, J. Appl. Phys., 2016, 120, 8563.

12 C. H. Phan, M. Mariatti and Y. H. Koh, J. Magn. Magn. Mater., 2016, 401, 472.

13 J. Liang, Y. Wang, Y. Huang, Y. F. Ma, Z. F. Liu, J. M. Cai, C. D. Zhang, H. J. Gao and Y. S. Chen, Carbon, 2009, 47, 922.

14 C. S. Chen, W. R. Chen, S. C. Chen and R. D. Chien, Int. Commun. Heat Mass Transfer, 2008, 35, 744.

15 K. Zhang, H. O. Yu, K. X. Yu, Y. Gao, M. Wang, J. Li and S. Y. Guo, Compos. Sci. Technol., 2018, 156, 136.

16 S. T. Tan, M. Q. Zhang, M. Z. Rong and H. M. Zeng, Polym. Compos., 1999, 20, 406.

17 J. Li, P. C. Ma, W. S. Chow, C. K. To, B. Z. Tang and J. K. Kim, Adv. Funct. Mater., 2007, 17, 3207.

18 J. Hone, M. C. Llaguno, M. J. Biercuk, A. T. Johnson, B. Batlogg, Z. Benes and J. E. Fischer, Appl. Phys. A: Mater. Sci. Process., 2002, 74, 339.

19 R. H. Baughman, A. A. Zakhidov and W. A. de Heer, Science, 2002, 297, 787.

20 Y. Li, C. Chen, S. Zhang, Y. Ni and J. Huang, Appl. Surf. Sci., 2008, 254, 5766.

21 G. P. Kar, S. Biswas, R. Rohini and S. Bose, J. Mater. Chem. A, 2015, 3, 7974.

22 A. Nazir, H. Yu, L. Wang, M. Haroon, R. S. Ullah, S. Fahad, K. R. Naveed, T. Elshaarani, A. Khan and M. Usman, J. Mater. Sci., 2018, 53, 1.

23 B. Wen, M. Cao, M. Lu, W. Q. Cao, H. L. Shi, J. Liu, X. X. Wang, H. B. Jin, X. Y. Fang, W. Z. Wang and J. Yuan, Adv. Mater., 2014, 26, 3484.

24 G. Wang, Z. Gao, S. Tang, C. Q. Chen, F. F. Duan, S. C. Zhao, S. W. Lin, Y. H. Feng, L. Zhou and Y. Qin, ACS Nano, 2012, 6, 11009.

25 R. C. Che, L. Peng, X. F. Duan, Q. Chen and X. L. Liang, Adv. Mater., 2004, 16, 401.

26 S. Gupta, C. Chang, C. H. Lai and N. H. Tai, Composites, Part $B, 2019,164,447$.

27 M. S. S. Dorraji, M. H. Rasoulifard, M. H. Khodabandeloo, M. Rastgouy-Houjaghan and H. K. Zarajabad, Appl. Surf. Sci., 2016, 366, 210.

28 W. Feng, Y. Wang, J. Chen, L. Wang, L. Guo, J. Ouyang, D. C. Jia and Y. Zhou, Carbon, 2016, 108, 52.

29 Q. Liu, Q. Cao, H. Bi, C. Liang, K. Yuan, W. She, Y. J. Yang and R. C. Che, Adv. Mater., 2016, 28, 486. 
30 H. Guan, C. Gang, S. Zhang and Y. Wang, Mater. Chem. Phys., 2010, 124, 639.

31 H. Guan, J. Xie J, G. Chen and Y. Wang, Mater. Chem. Phys., 2014, 143, 1061.

32 T. K. Gupta, B. P. Singh, V. N. Singh, S. Teotia, A. P. Singh, I. Elizabeth, S. R. Dhakate, S. K. Dhawanc and R. B. Mathur, J. Mater. Chem. A, 2014, 2, 4256.

33 Y. Wang, B. Han, N. Chen, D. Deng, H. Guan and Y. Wang, J. Alloys Compd., 2016, 676, 224.

34 P. J. Bora, K. J. Vinoy, P. C. Ramamurthy and G. Madras, Mater. Res. Express, 2017, 4, 025013.

35 P. J. Bora, I. Azeem, K. J. Vinoy, P. C. Ramamurthy and G. Madras, Composites, Part B, 2018, 132, 188.

36 M. Y. Li, S. Gupta, C. Chang and N. H. Tai, Composites, Part B, 2019, 161, 617.

37 S. Biswas, I. Arief, S. S. Panja and S. Bose, ACS Appl. Mater. Interfaces, 2017, 9, 3030.

38 H. Zhao, L. Hou, S. Bi and Y. Lu, ACS Appl. Mater. Interfaces, 2017, 9, 33059.

39 E. T. Thostenson and T. W. Chou, Carbon, 2006, 44, 3022.

40 M. J. Cui, S. M. Ren, G. A. Zhang, S. Liu, H. C. Zhao, L. P. Wang and Q. J. Xue, J. Chin. Soc. Corros. Prot., 2016, 36, 566 .
41 J. Q. Wei, B. Jiang, X. Zhang, H. W. Zhu and D. H. Wu, Chem. Phys. Lett., 2003, 376, 753.

42 T. Gupta, B. Singh, S. Dhakate, V. Singh and R. Mathur, J. Mater. Chem. A, 2013, 1, 9138.

$43 \mathrm{H}$. W. Ott, Electromagnetic Compatibility Engineering, John Wiley and Sons, 2009.

44 A. M. Nicolson and G. F. Ross, IEEE Trans. Instrum. Meas., 1970, 19, 377.

45 W. L. Song, M. S. Cao, M. M. Lu, S. Bi, C. Y. Wang, J. Liu, J. Yuan and L. Z. Fan, Carbon, 2014, 66, 67.

46 M. H. Al-Saleh and U. Sundararaj, Carbon, 2009, 47, 1738.

47 D. R. Smith, D. C. Vier, T. Koschny and C. M Soukoulis, Phys. Rev. E: Stat., Nonlinear, Soft Matter Phys., 2005, 71, 036617.

48 A. H. Boughriet, C. Legrand and A. Chapoton, IEEE Trans. Microwave Theory Tech., 1997, 45, 52.

49 V. Eswaraiah, V. Sankaranarayanan and S. Ramaprabhu, Nanoscale Res. Lett., 2011, 6, 137.

50 W. L. Song, M. S. Cao, Z. L. Hou, M. M. Lu, C. Y. Wang, J. Yuan and L. Z. Fan, Appl. Phys. A, 2014, 116, 1779.

51 H. Wang, Z. Zhang, C. Dong, G. Chen, Y. Wang and H. Guan, Sci. Rep., 2017, 7, 15841.

52 Y. Duan, Y. Yang, M. He, S. Liu, X. D. Cui and H. Chen, J. Phys. D: Appl. Phys., 2008, 41, 125403. 